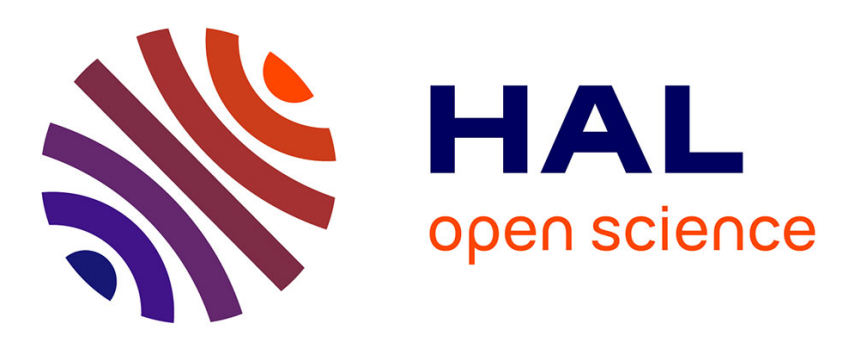

\title{
Stability of vertical films of molten glass due to evaporation
}

\author{
Franck Pigeonneau, Helena Kocarkova, Florence Rouyer
}

\section{To cite this version:}

Franck Pigeonneau, Helena Kocarkova, Florence Rouyer. Stability of vertical films of molten glass due to evaporation. Colloids and Surfaces A: Physicochemical and Engineering Aspects, 2012, 406, pp.1-19. 10.1016/j.colsurfa.2012.04.014 . hal-00709176

\section{HAL Id: hal-00709176 https://hal.science/hal-00709176}

Submitted on 18 Jun 2012

HAL is a multi-disciplinary open access archive for the deposit and dissemination of scientific research documents, whether they are published or not. The documents may come from teaching and research institutions in France or abroad, or from public or private research centers.
L'archive ouverte pluridisciplinaire HAL, est destinée au dépôt et à la diffusion de documents scientifiques de niveau recherche, publiés ou non, émanant des établissements d'enseignement et de recherche français ou étrangers, des laboratoires publics ou privés. 


\title{
Stability of vertical films of molten glass due to evaporation
}

\author{
F. Pigeonneau ${ }^{*, a}$, H. Kočárkováa ${ }^{a, 1}$, F. Rouyer ${ }^{\mathrm{b}}$ \\ ${ }^{a}$ Surface du Verre et Interfaces, UMR 125 CNRS/Saint-Gobain, 39 quai Lucien Lefranc - BP 135, \\ 93303 Aubervilliers cedex, France \\ ${ }^{b}$ Université Paris-Est, Laboratoire Navier (UMR CNRS 8205, Ecole des Ponts Paris Tech, \\ IFSTTAR), 5 bd Descartes, 77454 Marne-la-Vallée, France
}

\begin{abstract}
First, we report observations achieved on a gravitationally-driven film drainage with molten glass pointing out a stabilizing effect when temperature is larger than $1250^{\circ} \mathrm{C}$. A model to describe the change of surface tension with the film thickness due to the evaporation of oxide species is proposed. A lubrication model is derived taking into account the gradient of surface tension. The final system of equations describing the mass and the momentum conservations is numerically solved by an implicit time solver using a finite difference method at a second order scheme in time and space.

The numerical procedure is applied to study a film drainage of molten soda-lime-silica glass. The effect of the surface tension gradient is investigated pointing out that with an increase of $0.5 \%$ of the surface tension over the spread of the film which is order of few centimeters, the liquid film reaches an equilibrium thickness in agreement with previous experimental work.
\end{abstract}

Key words: foam, film drainage, Marangoni effect, glass, stability, evaporation

\section{Introduction}

Foams are dispersions of gas bubbles in a liquid matrix. Foams have several very interesting and unusual properties which make them possible candidates for use in many industrial applications. In most of cases, the stability of foam is a required property.

\footnotetext{
${ }^{*}$ Corresponding author: Tel. +33 (1) 483959 99, Fax +33 (1) 48395562.

Email addresses: franck.pigeonneau@saint-gobain.com (F. Pigeonneau), helena@ecoglass.cz (H. Kočárková), florence.rouyer@univ-mlv.fr (F. Rouyer)

${ }^{1}$ Present address: EcoGlass, a.s., Arbesova 66a, 46604 Jablonec nad Nisou (Czech Republic) Preprint submitted to Colloids Surf., A 
Today, many investigations are devoted to the creation of stable foams [7]. Nevertheless, in glass melting process in particular, foam can be a nuisance. Most of glass furnaces are heated by a combustion chamber above the glass bath. Consequently, if a large part of the bath surface is covered with foam, heat transfer, mainly radiative due to the high temperature, decreases due to the thermal insulator property of glass foam [38]. Consequently, the optimization of the industrial plants needs to improve the knowledge of the physical grounds playing an important role in the foam stability.

Glass melting is a chemical process for which glass is made in most of cases with silica, soda ash, and lime [33]. The raw materials are generally carbonaceous elements giving a carbon dioxide release. The low solubility of $\mathrm{CO}_{2}$ leads to a creation of large quantity of bubbles entrapped in a molten glass. To remove these gaseous inclusions, sulfate compounds are added to raw materials. Thus gases released by sulfate decomposition lead to a bubble growth. Due to buoyancy forces, larger bubbles can escape from bath surface more rapidly [33].

The onset of glass foaming has been studied by Kim and Hrma [16]. From a knowledge of chemical reactions produced by sulfate species, they determined the foaming temperature. Pilon [24] developed a model to study the foam formation by bubbling and established a relationship between foam layer and physical properties of liquid using a dimensional analysis. Foams in the glass melting process have been recently reviewed by Pilon [23] giving a large overview where many references can been found.

Foam aging is related to the liquid film stability formed between bubbles. A liquid film can be created under various size, shape and spatial orientation as it has been reviewed by Exerowa and Kruglyakov [11]. Initiated by the work of Mysel et al. [20], a liquid film formed on a vertical frame has been extensively studied. The influence of surfactants in aqueous solutions has been experimentally investigated by studying the film thickness as a function of the velocity at which the film is pulled out in $[19,8,3]$ and more recently by Saulnier et al. [29]. Mathematical models to describe the two-dimensional draining film have been studied by various authors as for instance Schwartz and Roy [32] investigating mobile and immobile soap films. Howell [14] presented a general method to obtain lubrication model of thin film in various situations with free shear stresses on interfaces. An important contribution has been done by the team of Braun $[5,4,21]$ 
studying the drainage of vertical film taking into account the Marangoni stress and the transport of surfactant agent. The law describing the film thickness as a function of the pulling-out velocity and physical properties including surface rheology has been studied by van Nierop et al. $[36,37]$. The role played by thermal gradient on the surface tension has been recently studied by Scheid et al. [30]. They shown that it is possible to form a stable liquid film controlled by a surface tension gradient.

Kappel et al. [15] achieved an experimental study about film drainage on molten glass. They found that the film thickness decreases exponentially with time. They observed a stabilization state leading to a film thickness around one hundred nanometers. Laimböck [18] did a similar experiments where film thicknesses were determined by electric resistivity. He found that glass film can reach a stabilized thickness in the same order of magnitude found by Kappel et al. [15]. Laimböck proposed a model to explain the film stability. He pointed out an adsorption of sodium oxide at the free surfaces of the liquid film. After a simple model to explain the change of surface tension, a static equilibrium between the gravity and surface tension forces is written over the length of the liquid film. As we will see later our observations invalidate the adsorption of sodium oxide.

Despite these contributions, investigations have seldom been done on the mathematical model to describe the stabilization of the vertical molten glass film. So, the purpose of this work is to study the drainage of a vertical film dynamically. Based on experimental observations, the feature of surface tension as a function of the film thickness is proposed. A lubrication model in which the surface tension gradient is introduced according to the prior developments of Howell [14] and Breward [6].

The section 2 reports an experiment achieved on a vertical film drainage where a stability of molten glass film has been observed. Section 3 is devoted to the modeling of the evolution of the surface tension as a function of the film thickness due to evaporation of surface active species. The lubrication model is presented in section 4 . Numerical results including the two previous developments and discussion are detailed in section 5 before to conclude. 
Top view

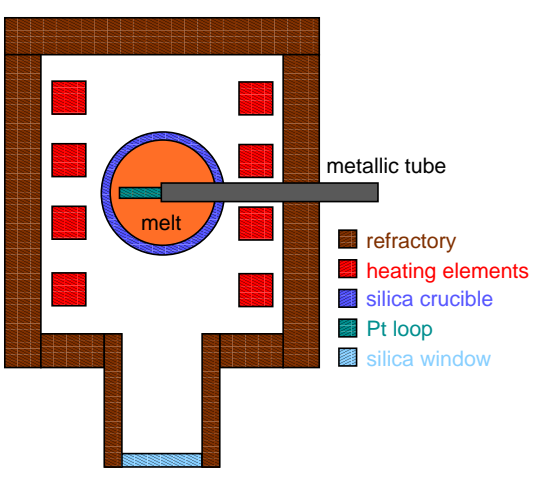

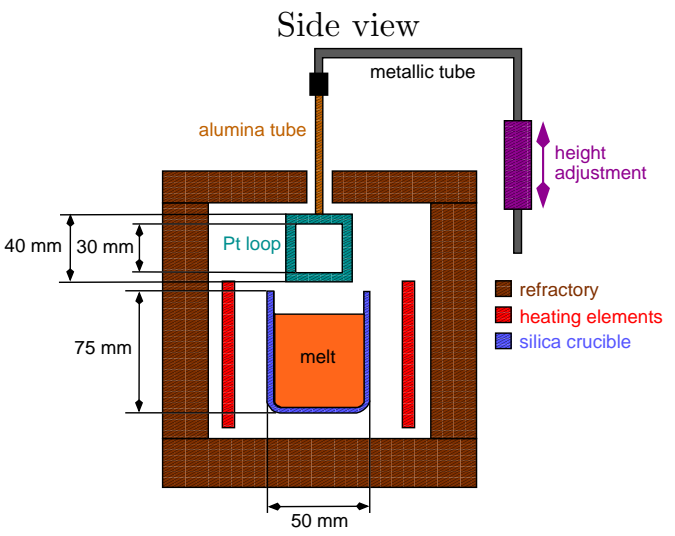

Figure 1: Experimental set-up for vertical film in molten glass (top and side views).

\begin{tabular}{cccccc}
\hline $\mathrm{SiO}_{2}$ & $\mathrm{Na}_{2} \mathrm{O}$ & $\mathrm{CaO}$ & $\mathrm{K}_{2} \mathrm{O}$ & $\mathrm{MgO}$ & $\mathrm{Al}_{2} \mathrm{O}_{3}$ \\
\hline 72.1 & 13.3 & 9 & 0.1 & 3.6 & 0.8
\end{tabular}

Table 1: Composition given in weight percentage of glass used in the film drainage experiments.

\section{Experiment of vertical film drainage of molten glass}

We performed a gravitationally-driven film drainage experiment achieved on molten glass film created with a squared frame of $3 \mathrm{~cm}$ side and $1 \mathrm{~mm}$ thick made of an alloy of Platinum and Rhodium. A top and side views of the sketch of the laboratory furnace are shown in Figure 1. Observation of the experiment is enabled via silica window, which is placed in the front part of the furnace, see the top view of Figure 1. Molten glass is introduced in a transparent silica crucible enabling the controlled motion of the Platinum-Rhodium loop inside the pool. Experiments are done in the temperature range from 1100 to $1300^{\circ} \mathrm{C}$. Due to this high temperature surrounding and great difficulties to control film position, the thickness measurement by an optical method was not achieved. However, throughout the experiment, a recording with CCD video camera is done in which a narrow band filter is added in the optical objective to remove the thermal radiation. This recording allows to determine the film lifetime as well as to observe flow patterns in the film.

A commercial oxide glass has been studied: its composition in term of main oxides is given in Table 1. The main applications of this glass are in habitat and in automotive.

The lifetimes of the liquid film have been recorded for five temperatures for which the 
experiment is repeated four times. The lifetime, $t_{\text {life }}$, as a function of temperature is given in Figure 2. Since the lifetime is mainly controlled by the viscous drainage driven by the gravity, we expect that the lifetime decreases with temperature because the viscosity decreases with temperature. This is verified while temperature is smaller than $1250^{\circ} \mathrm{C}$ in Figure 2-a. However, for temperature larger than $1250^{\circ} \mathrm{C}$, the lifetime increases with the temperature. In aim to quantify this unexpected behavior, we compare the lifetime measured experimentally to the time scale based on a lubrication model of gravitational drainage for a $2 \mathrm{D}$ film with free surfaces that will be explained in details in $\S 4$. Thus, the lifetime is normalized by $\rho g L / \mu$ where $\rho$ is the liquid density, $g$ the gravitational constant, $L$ the height of the liquid film and $\mu$ the dynamic viscosity. The film thickness does not appear in this time scale because the interfaces are shear free meaning that the flow in the film liquid is a pure extensional flow. As it is well-known in this situation, the time scale arises from the balance of the gravity and extensional viscosity forces for which the film thickness is an irrelevant quantity [14]. However the lifetime of the film depends on initial thickness and critical thickness at rupture that are both assumed to be independent of temperature. Indeed, the initial thickness would depend essentially on frame thickness when the film is pulled slowly. The critical thickness at rupture would depend on the film size, the Hamaker constant and the surface tension [39, 26]. In case of molten glass, this thickness is reported of the order of $100 \mathrm{~nm}$ [35]. Figure 2-b shows that the normalized lifetime does not change significantly with temperature and that it is equal to few hundreds while temperature is less than $1150^{\circ} \mathrm{C}$. However, for larger temperature, the normalized lifetime increases strongly with the temperature. At $T=1300^{\circ} \mathrm{C}$, the lifetime is very important since it is larger than 2500 times the time scale of drainage.

These experimental results show that a physical mechanism, occurring at temperature larger than $1150^{\circ} \mathrm{C}$, is able to slow down the film drainage or stabilize the film and that its effect increases with temperature. Figure 3 is a serial of snapshots taken every 20 seconds with a black background. The bright part around the liquid film is the PlatinumRhodium loop. On the bottom of each picture, the white part is the top of the crucible. Moreover, fringes on the film surface shown in Figure 3 appear and move with time ${ }^{2}$.

\footnotetext{
${ }^{2}$ The supplementary materials can be downloaded in the website of the journal to see a movie of an
} 5 
a)

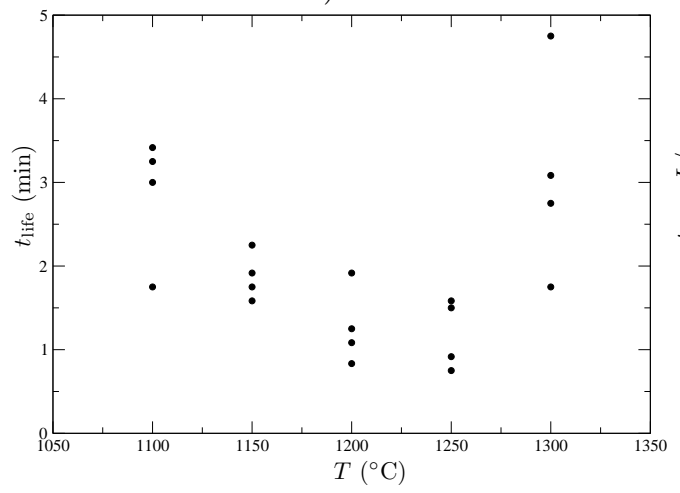

b)

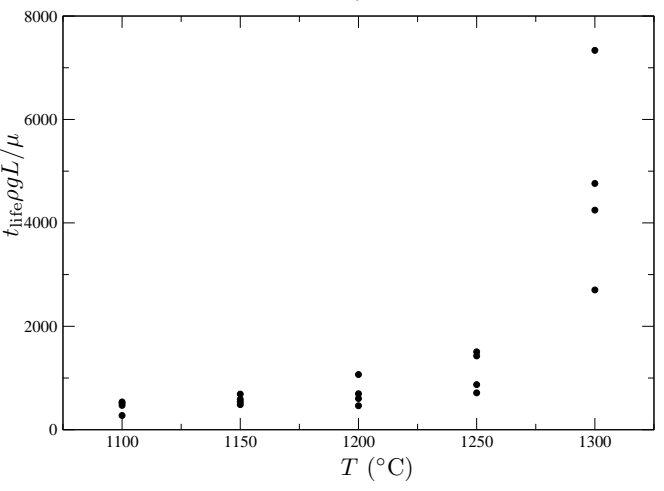

Figure 2: a) Lifetime of the vertical molten glass film versus temperature inside the furnace. b) Normalized lifetime of the vertical molten glass film versus temperature inside the furnace.

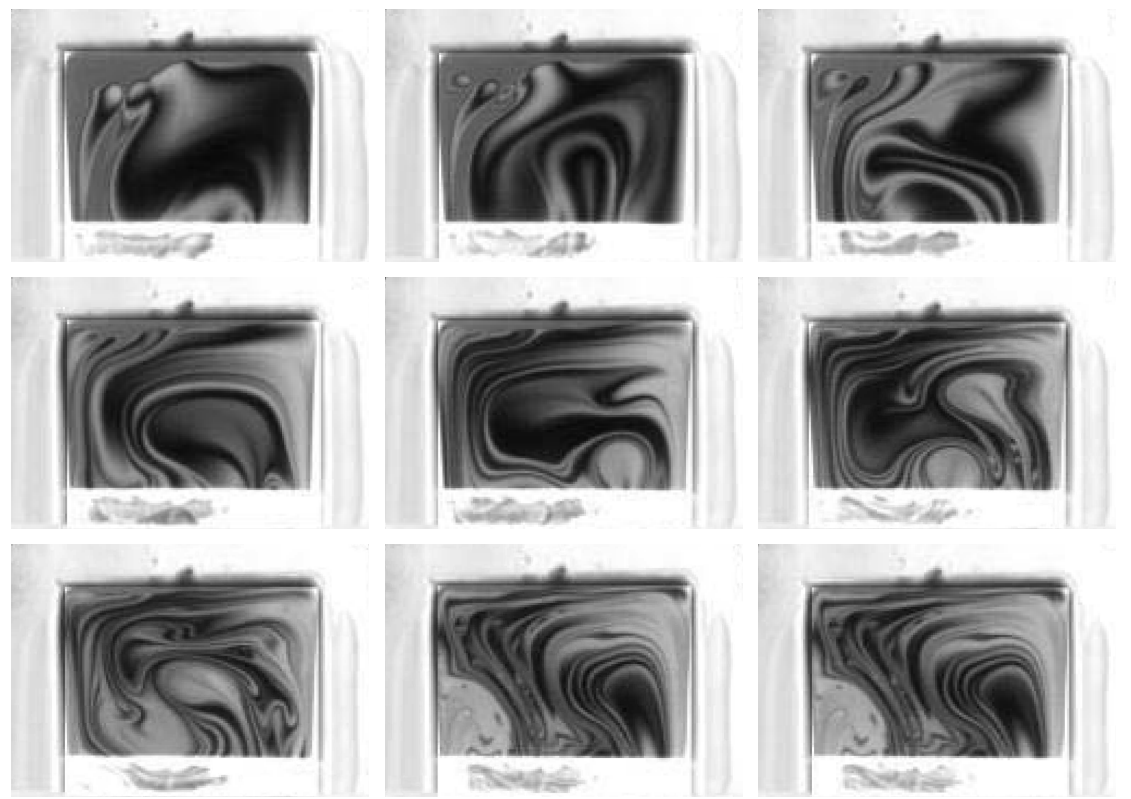

Figure 3: Snapshots of a glass film during an experiment achieved at $T=1300^{\circ} \mathrm{C}$. Snapshots are spaced of 20 seconds. The chronometric order is from left to right and from top to bottom. 
The film thickness stabilization and the motions can be due to a variation of the surface tension. The thermal homogeneity in the furnace over the length of the PlatinumRhodium loop used in the experiment is well controlled to ensure that the motion is not driven by a heat phenomena. We argue that the surface tension changes due to a chemical process and is dominant compared to thermal effect.

In order to confirm the last assertion, experiments which pull a thin film out of the molten glass bath has been repeated but the molten glass film has been taken out before its rupture, and quenched. After annihilation of the mechanic stresses in the film, an analysis has been achieved using a Secondary Ion Mass Spectrometry (SIMS) technique. In this method, a focused primary ions beam are launched onto the surface of the sample. The analysis thanks to a mass spectrometer of the ejected secondary ion gives the composition of the surface of the sample, see for more details [40]. Depth profiling is done by use of two ion beams that operate simultaneously. While the first beam is sputtering a crater, the second beam is progressively analyzing the crater bottom. Our spectrometer works with either a cation of $\mathrm{Bi}^{+}$or a cluster of $\mathrm{Bi}^{+}$as primary ion and has been purchased from ION-TOF GmbH. Figure 4 presents the $\mathrm{Na}_{2} \mathrm{O}$ content through the film obtained at 1200 and $1400^{\circ} \mathrm{C}$ after a calibration of the intensity recorded by the spectrometer (details of the determination of $\mathrm{Na}_{2} \mathrm{O}$ content can be found in [17]). The content of $\mathrm{Na}_{2} \mathrm{O}$ is smaller at the interface meaning an evaporation of this oxide. The content at the interface decreases with the temperature. Furthermore, the typical scale over which the $\mathrm{Na}_{2} \mathrm{O}$ changes is more important at high temperature. The scale over which $\mathrm{Na}_{2} \mathrm{O}$ changes is noted $\delta$ as represented in Figure 4. The decrease of $\mathrm{Na}_{2} \mathrm{O}$ close to the interfaces is followed by an increase of $\mathrm{SiO}_{2}$ and $\mathrm{CaO}$ over the same depth.

The noteworthy point is that our measurements are in disagreement with the one reported by Laimböck [18]. Indeed, using XPS technique with an ion gun, Laimböck [18] observed that the glass composition over the film thickness changes significantly: the $\mathrm{Na}_{2} \mathrm{O}$ content increases strongly at the film interface while the $\mathrm{SiO}_{2}$ content decreases. This disagreement can be due to the glass nature. In the current study, the industrial glass is used whilst Laimböck [18] studied a ternary glass. The other source of disagreement could come from the analysis techniques which are different.

experiment. 


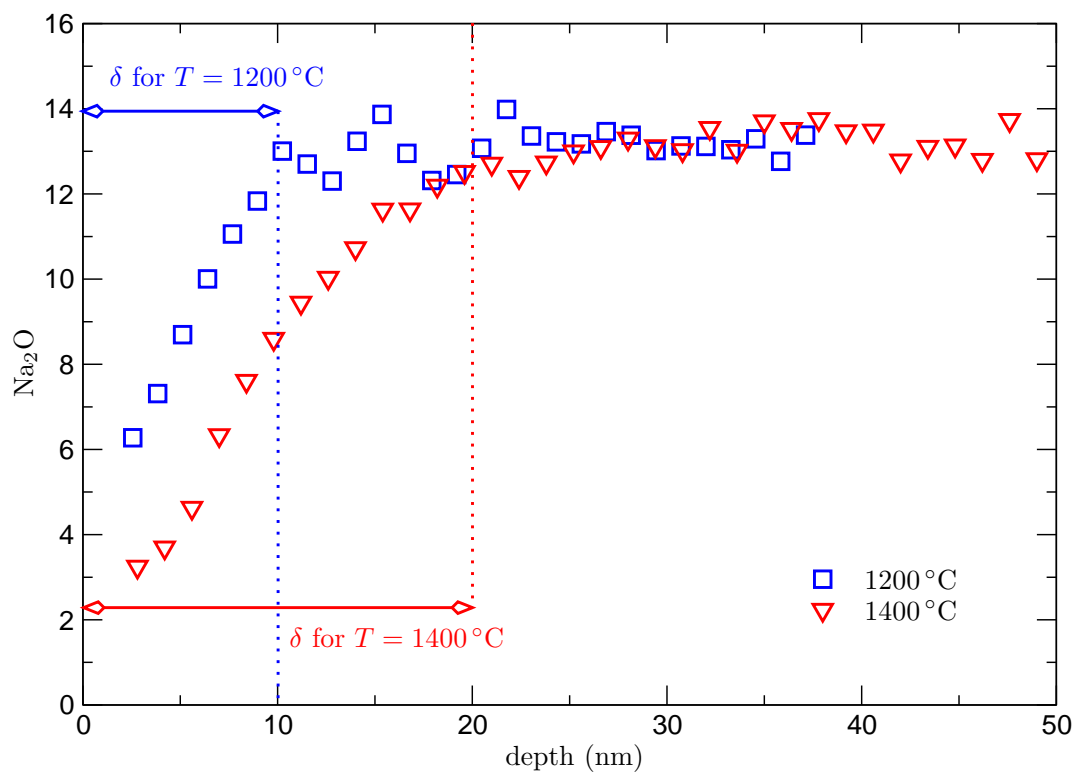

Figure 4: $\mathrm{Na}_{2} \mathrm{O}$ content as a function of the depth in the film for two temperature.

However, recall that $\mathrm{Na}_{2} \mathrm{O}$ is known to be a volatile species $[28,1]$. The evaporation of $\mathrm{Na}_{2} \mathrm{O}$ leads to a modification of the glass composition at the interface. The evaporation of $\mathrm{Na}_{2} \mathrm{O}$ is generally explained by a heterogeneous chemical reaction between water vapor and sodium oxide giving sodium hydroxide, $\mathrm{NaOH}$. Consequently, it is expected to observe a positive gradient of $\mathrm{Na}$ over the depth of the film as it is measured in our chemical analysis.

The evaporation of chemical species leading to a Marangoni phenomena has been previously studied by Berg et al. [2] to investigate the patterns observed in horizontal liquid layers heated from below. The evaporating or condensing films have been also reviewed by Oron et al. [22]. The climbing films occurring for instance in the evaporative alcohol solutions have been also studied experimentally and theoretically by Hosoi and Bush [13].

The evaporation of $\mathrm{Na}_{2} \mathrm{O}$ leads to a change in the nature of glass and in consequence of what the surface tension does not stay uniform in space. This phenomena can explain the increase of the lifetime of the liquid film. The following of this article is devoted to the demonstration of the effect of the evaporation process of $\mathrm{Na}_{2} \mathrm{O}$ on the film stability thanks to a simple model to describe the surface tension changes with film thickness. 


\section{Surface tension in molten glass and variation with the film thickness}

The volatilization of sodium oxide involves a heterogeneous chemical reaction with nonlinear behaviors of mass fluxes. Moreover, the full problem implies transient diffusion process with a mass transfer coefficient between the film and the atmosphere difficult to evaluate. So, the aim of this section is to provide a simple model to describe the variation of the surface tension as a function of film thickness.

According to an additivity principle, Scholze [31] writes the surface tension of glass as follows:

$$
\gamma=\sum_{i=1}^{N} \gamma_{i} y_{i},
$$

where $\gamma$ is the surface tension, $N$ is the number of oxides in the glass composition, $y_{i}$ the mass fraction of the oxide $i$ and $\gamma_{i}$ is a factor corresponding to the contribution of the oxide $i$ in the surface tension given in $\mathrm{N} / \mathrm{m}$.

Since the surface tension is determined from the bulk quantities and that $\mathrm{Na}_{2} \mathrm{O}$ evaporate, we consider the volatilization of $\mathrm{Na}_{2} \mathrm{O}$ to describe the change of surface tension. When the film is pulled out, the volatilization occurs leading to a decrease of $\mathrm{Na}_{2} \mathrm{O}$ concentration. To determine this quantity for a portion of film of volume $V$ and constant thickness $h$, the mass balance before and after the evaporation is given by

$$
\rho_{\mathrm{Na}_{2} \mathrm{O}, 0} V=\rho_{\mathrm{Na}_{2} \mathrm{O}} V+2 \frac{d m_{\mathrm{Na}_{2} \mathrm{O}}}{d S} S
$$

in which $\rho_{\mathrm{Na}_{2} \mathrm{O}, 0}$ is the mass concentration of $\mathrm{Na}_{2} \mathrm{O}$ in the bulk and $\rho_{\mathrm{Na}_{2} \mathrm{O}}$ the mass concentration in the liquid film, $V$ the volume of the film and $S$ the area of each interface. Finally, $d m_{\mathrm{Na}_{2} \mathrm{O}} / d S$ is the mass loss by unit surface. Since the ratio of $S$ over $V$ is directly the film thickness, $h$, the last equation can be written as follows

$$
\rho_{\mathrm{Na}_{2} \mathrm{O}, 0} h=\rho_{\mathrm{Na}_{2} \mathrm{O}} h+2 \frac{d m_{\mathrm{Na}_{2} \mathrm{O}}}{d S} .
$$

This equation is similar in appearance to the one used to describe the soap films just after the pulling out but with different physics [10]. To close this equation, we assume that the loss of mass is proportional to $\rho_{\mathrm{Na}_{2} \mathrm{O}}$ inside the portion of film of thickness $h$ and 
to the size $\delta$ over which the volatilization occurs as introduced in the previous section:

$$
\frac{d m_{\mathrm{Na}_{2} \mathrm{O}}}{d S}=\delta \rho_{\mathrm{Na}_{2} \mathrm{O}}
$$

This assumption is similar to the Langmuir isotherm used by Ruckenstein and Jain [26] to study the rupture of thin liquid film with a soluble surface active agents. Remark that Laïmbock [18] took the same approximation assuming the the sodium oxide is adsorbed whereas we argue that the sodium oxide is evaporated. By combining Eqs. (3) and (4), the mass concentration of $\mathrm{Na}_{2} \mathrm{O}$ in a portion of film of thickness $h$ is given by

$$
\rho_{\mathrm{Na}_{2} \mathrm{O}}=\frac{\rho_{\mathrm{Na}_{2} \mathrm{O}, 0}}{1+2 \delta / h}
$$

So, this phenomenological relationship leads to a closed equation to describe the mass concentration of $\mathrm{Na}_{2} \mathrm{O}$ as a function of the film thickness. Finally, the difference of mass concentration of $\mathrm{Na}_{2} \mathrm{O}$ in a film of thickness $h$ and the bulk that will be used to describe the change of surface tension, is given by

$$
\rho_{\mathrm{Na}_{2} \mathrm{O}}-\rho_{\mathrm{Na}_{2} \mathrm{O}, 0}=-\frac{\rho_{\mathrm{Na}_{2} \mathrm{O}, 0}}{1+h /(2 \delta)} .
$$

This last equation can be used to evaluate the feature of surface tension as a function of film thickness. Indeed, if we assume that the surface tension changes only due to the mass concentration of $\mathrm{Na}_{2} \mathrm{O}, \mathrm{SiO}_{2}$ and $\mathrm{CaO}$ which are the main oxides in the glass, the difference between the surface tension for a very thin film, $\gamma$, and a surface tension of bulk glass, $\gamma_{0}$, is given according to (1) by

$$
\gamma-\gamma_{0}=\gamma_{\mathrm{Na}_{2} \mathrm{O}}\left(y_{\mathrm{Na}_{2} \mathrm{O}}-y_{\mathrm{Na}_{2} \mathrm{O}, 0}\right)+\gamma_{\mathrm{SiO}_{2}}\left(y_{\mathrm{SiO}_{2}}-y_{\mathrm{SiO}_{2}, 0}\right)+\gamma_{\mathrm{CaO}}\left(y_{\mathrm{CaO}}-y_{\mathrm{CaO}, 0}\right) .
$$

By assuming that the decrease of the concentration of $\mathrm{Na}_{2} \mathrm{O}$ is compensated by the increase of $\mathrm{SiO}_{2}$ and $\mathrm{CaO}$ proportionally to their mutual initial weight ratio, the surface tension becomes

$$
\gamma=\gamma_{0}+\delta \gamma f_{\gamma}(h / 2),
$$


where $\delta \gamma$ is given by

$$
\delta \gamma=\left(\gamma_{\mathrm{SiO}_{2}} \frac{y_{\mathrm{SiO}_{2}, 0}}{y_{\mathrm{SiO}_{2}, 0}+y_{\mathrm{CaO}, 0}}+\gamma_{\mathrm{CaO}} \frac{y_{\mathrm{CaO}, 0}}{y_{\mathrm{SiO}_{2}, 0}+y_{\mathrm{CaO}, 0}}-\gamma_{\mathrm{Na}_{2} \mathrm{O}}\right) y_{\mathrm{Na}_{2} \mathrm{O}, 0}
$$

and $f_{\gamma}(\chi)$, where $\chi \in[-h / 2 ; h / 2]$, is an even function given by

$$
f_{\gamma}(\chi)=\frac{1}{1+|\chi| / \delta}
$$

From the factors $\gamma_{\mathrm{SiO}_{2}}, \gamma_{\mathrm{CaO}}$ and $\gamma_{\mathrm{Na}_{2} \mathrm{O}}$ provided in [31, 25] and with the glass composition given in Table $1, \delta \gamma$ is a positive quantity meaning that the surface tension given

by (8) increases when the film thickness decreases. While the scale, $\delta$, over which the sodium oxide evaporates depends on temperature, the quantity $\delta \gamma$ is only a function of the glass nature. Its value is equal to $4.2 \cdot 10^{-2} \mathrm{~N} / \mathrm{m}$ whilst the surface tension $\gamma_{0}$ is equal to $3.2 \cdot 10^{-1} \mathrm{~N} / \mathrm{m}$ for the largest temperature $T=1400^{\circ} \mathrm{C}$. According to this modeling, the relative increase of surface tension is at the maximum equal to $1.5 \%$ for $h \rightarrow 0$ and of the order of $0.5 \%$ for $h \simeq 5 \delta$. This last value seems appropriate for quantifying the Marangoni stress due to evaporation for thin film whose thickness $h \sim 100 \mathrm{~nm}$ and whose $\mathrm{Na}_{2} \mathrm{O}$ variation is observed over a depth equal to $20 \mathrm{~nm}$.

\section{Extensional flow model of 2D-Cartesian film}

The situation addressed in this section is shown in Fig. 5 where a vertical film is attached to a horizontal wire in $x=0$. The quantity $x$ represents the longitudinal direction relative to the height of the film while $y$ is the transversal coordinate relative to its thickness. Moreover, the vertical axis $(y=0)$ is axis of symmetry. Under the gravity force, directed along $x$, the film thickness, $h$ is a function of the time $t$ and of position $x$. The film has a height equal to $L$ and falls in a liquid pool. In the following, the film thickness $H_{0}$ on $x=0$ is assumed to be very small compare to the height $L$.

A lubrication model is used to study the drainage of the liquid film under the assumption that the interface behaves as a free surface. The derivation of the lubrication model has been done by different authors starting by the first study achieved by Trouton [34]. In the situation of 2D-Cartesian film, two unknowns are involved: $h(x, t)$, the film thickness, and $u(x, t)$, the cross-sectionally averaged velocity. The two equations describing 


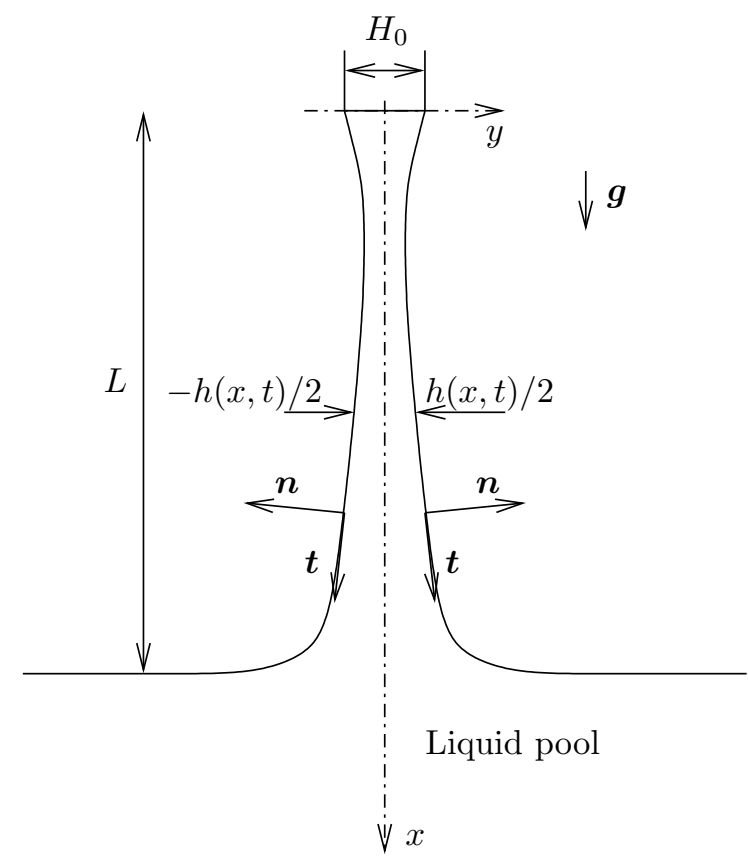

Figure 5: Liquid film draining under the gravity force. Figure is not on scale.

the mass and the momentum are $[14,6,22]$

$$
\begin{aligned}
\frac{\partial h}{\partial t}+\frac{\partial(h u)}{\partial x} & =0 \\
\rho h\left(\frac{\partial u}{\partial t}+u u_{, x}\right) & =4 \mu \frac{\partial\left(h u_{, x}\right)}{\partial x}+\frac{\gamma h h_{, x x x}}{2}+\delta \gamma \frac{d f_{\gamma}}{d \chi} h_{, x}+\rho g h
\end{aligned}
$$

where $\rho$ is the liquid density, $\mu$ the dynamic viscosity, $g$ is the gravitational constant and the subscript,$x$ denotes the partial derivative over $x$. The left hand side of the momentum equation is the inertia term. The first term of the right hand side of (12) is the viscous force in which the factor 4 is the Trouton coefficient [34] for the $2 \mathrm{D}$ plane situation, the second term is the force due to the curvature gradient, the third is the contribution due to the surface tension gradient where $\delta \gamma$ and $f_{\gamma}$ have previously been introduced. Finally, the last term is the gravity force.

The equations are normalized by assuming that the driven forces are the gravity and viscous terms. In this case, the characteristic velocity is $U_{0}=\rho g L^{2} / \mu$. The dimensionless 
variables are written as follows

$$
\bar{x}=\frac{x}{L}, \bar{h}=\frac{h}{H_{0}}, \bar{u}=\frac{u}{U_{0}}, \bar{t}=\frac{t U_{0}}{L} .
$$

Eq. (12) becomes

$$
\operatorname{Re} \bar{h}\left(\frac{\partial \bar{u}}{\partial \bar{t}}+\overline{u u}_{, \bar{x}}\right)=4 \frac{\partial\left(\bar{h} \bar{u}_{, \bar{x}}\right)}{\partial \bar{x}}+\frac{\bar{\gamma} \overline{h h}_{, \overline{x x x}}}{2 \text { Bo }}+\mathrm{Ma} \frac{d f_{\bar{\gamma}}}{d \chi} \bar{h}_{, \bar{x}}+\bar{h}
$$

where the Reynolds, Bond and Marangoni numbers are respectively given by

$$
\mathrm{Re}=\frac{\rho U_{0} L}{\mu}, \mathrm{Bo}=\frac{\rho g L^{3}}{\gamma_{0} H_{0}}, \mathrm{Ma}=\frac{\delta \gamma}{\mu U_{0}} .
$$

The dimensionless surface tension, $\bar{\gamma}$, is given by

$$
\bar{\gamma}=1+\overline{\delta \gamma} f_{\gamma}(\bar{h} / 2)
$$

where

$$
\overline{\delta \gamma}=\frac{\delta \gamma}{\gamma_{0}}
$$

and $f_{\bar{\gamma}}(\chi)$ is a dimensionless even function defined according to the development detailed in $\S 3$ and given by:

$$
f_{\bar{\gamma}}(\chi)=\frac{1}{1+|\chi| / \bar{\delta}}
$$

where $\bar{\delta}=\delta / H_{0}$.

Eqs. (11), and (14) must be completed by boundary conditions. At the top of the film, the thickness and the velocity are specified (Dirichlet conditions):

$$
\begin{aligned}
& \bar{h}(0, \bar{t})=1, \\
& \bar{u}(0, \bar{t})=0 .
\end{aligned}
$$

Since the purpose is to determine the film thickness profile of the entire film, the matching with the liquid pool must be described thanks to the boundary conditions written on the bottom of the film. As already shown in $[27,41]$, it is possible to match 
with the pool by assuming that the equation of the static meniscus

$$
\bar{\kappa}_{, \bar{x}}=\frac{1}{{\overline{l_{c}}}^{2}}
$$

is verified. The reduced capillary length, $\overline{l_{c}}$, is defined by

$$
\overline{l_{c}}=\frac{1}{L} \sqrt{\frac{\gamma_{0}}{\rho g}}
$$

and the curvature, $\bar{\kappa}$, by

$$
\bar{\kappa}=-\frac{\epsilon \bar{h}_{, \overline{x x}}}{2\left(1+\epsilon^{2} \bar{h}_{, \bar{x}}^{2} / 4\right)^{3 / 2}},
$$

in which $\epsilon$ is the aspect ratio equal to $H_{0} / L$.

By multiplying Eq. (21) by $\bar{\kappa}$ and integrating over $\bar{x}$, the following relationship is obtained

$$
\bar{\kappa}^{2}=-\frac{\epsilon \bar{h}}{\bar{l}_{c}^{2} \sqrt{1+\epsilon^{2} \bar{h}_{, \bar{x}}^{2} / 4}}+\frac{A}{{\overline{l_{c}}}^{2}},
$$

where $A$ is an integration constant.

For a film falling in a large pool, the free surface can be considered as flat meaning that $\bar{h}_{\bar{x}}$ goes to infinity when $\bar{x} \rightarrow 1$. Since the curvature must be equal to zero when $\bar{x} \rightarrow 1, A$ must be equal to $2[27,5,4]$.

According to the previous works of Braun et al. [5, 4], a matching between the liquid film described by the momentum equation (14) and the static meniscus can be achieved by specifying the first and the second derivatives of $\bar{h}$. We specify the first derivative of $\bar{h}$ at the bottom of the film as

$$
\bar{h}_{, \bar{x}}(1, \bar{t})=\alpha .
$$

According Eqs. (23) and (24), the second derivative is given by

$$
\bar{h}_{, \overline{x x}}(1, \bar{t})=\beta=\frac{2}{\epsilon \overline{\bar{l}_{c}}} \sqrt{\left(2-\frac{\epsilon \alpha}{\sqrt{1+\epsilon^{2} \alpha^{2} / 4}}\right)\left(1+\epsilon^{2} \alpha^{2} / 4\right)^{3}} .
$$

These two relationships are used as boundary conditions at the bottom.

This is an asymptotic patch since by imposing $\bar{h}_{, \bar{x}}$ and $\bar{h}, \overline{x x}$, the matching occurs only 
at a single point localized in the area close to the "real" free surface of the pool. The distance from the free surface for which the matching occurs could be approximated by the position where the slope of the static profile is equal to $\alpha$. According to Heller [12] who determined the profile of a static vertical film, the matching distance, $\bar{x}_{*}=1-\bar{x}$, is given by the relationship:

$$
\bar{x}_{*}=\sqrt{2 \bar{l}_{c}} \sqrt{1-\frac{\alpha \epsilon}{\sqrt{4+(\alpha \epsilon)^{2}}}},
$$

This distance is proportional to the capillary length and would be smaller and smaller when the product $\alpha \epsilon$ is larger and larger. In the numerical applications provided latter, $\bar{x}_{*}$ will be equal to few percent of the film length. Note that neither a value, nor a flux for the velocity are imposed on the bottom of the film.

At the initial time, $\bar{h}$ is imposed equal to one where the matching with the static meniscus is achieved using

$$
\bar{h}(\bar{x}, 0)=1,
$$

for $\bar{x} \in\left[0 ; \bar{x}_{c}\right]$ and

$$
\bar{h}(\bar{x}, 0)=1-(\alpha-\beta) \bar{x}_{c}-\frac{\beta \bar{x}_{c}^{2}}{2}+(\alpha-\beta) \bar{x}+\frac{\beta \bar{x}^{2}}{2},
$$

for $\left.\bar{x} \in] \bar{x}_{c} ; 1\right]$ where $\alpha$ and $\beta$ are the coefficients used in the boundary conditions on $\bar{x}=1$ given previously and $\bar{x}_{c}$ is equal to

$$
\bar{x}_{c}=1-\frac{\alpha}{\beta} .
$$

The velocity $\bar{u}$ is assumed to be equal to zero at $\bar{t}=0$.

The coupled equations (11) and (14) are solved numerically using a finite difference method. The spatial derivatives are determined by the second order schemes given in [9] using unsymmetric schemes close to the top and the bottom for the second and third derivatives. The nonlinear system is solved using a Newton-Raphson algorithm. 


\section{Numerical results and comparison to experiments}

This section is devoted to the results obtained for the numerical simulations applied on the drainage of vertical film connected to the liquid pool.

The drainage of vertical film is investigated by solving the coupled equations (11) and (14) with the conditions given by Eqs. (19), (20), (25) and (26). The physical properties are taken from data corresponding to the glass composition given in Table 1. The density is equal to $2350 \mathrm{~kg} / \mathrm{m}^{3}$, the dynamic viscosity is equal to $50 \mathrm{~Pa} \cdot \mathrm{s}$, corresponding to molten glass at $1240{ }^{\circ} \mathrm{C}$. The surface tension, $\gamma_{0}$ is equal to $0.32 \mathrm{~N} / \mathrm{m}$ using the correlation factors given by Rubenstein [25]. The length and the initial thickness of the liquid film are respectively $L=3 \cdot 10^{-2} \mathrm{~m}$ and $H_{0}=10^{-3} \mathrm{~m}$. With these characteristic values, the Bond number is equal to $1.94 \cdot 10^{3}$ and the Reynolds number to $5.85 \cdot 10^{-1}$.

Since the connection to the liquid pool is achieved artificially using the boundary conditions (25) and (26), we first present a study on the influence of $\alpha$ on the drainage in $\S 5.1$. The second part of this section will be devoted to the contribution of the surface tension gradient on the vertical drainage.

\subsection{Effect of the boundary conditions at the bottom}

In this subsection, the surface tension is assumed uniform but the boundary conditions at the bottom of the film (parameter $\alpha$ ) is varied in aim to study its influence on the evolution in space and time of the film thickness.

Figure 6 represents the minimum of $\bar{h}$ in the liquid film as a function of time for three value of $\alpha$. The film thickness decreases rapidly in the first times $(\bar{t}<50)$. For long times $(\bar{t}>50)$ the thinning rate is slower than at first times. The first decrease is mainly due to the initial condition assuming the uniform thickness. Close to the top of the liquid film a meniscus appears as soon as the drainage starts as it is shown in Figure 7. The second part of the thinning process is a properly speaking due to the drainage. As expected, the film thickness decreases exponentially with the time due to the pure extensional flow in a film with stress free surfaces. The effect of the boundary conditions at the bottom has a small influence on the drainage of the liquid film at its minimal thickness. The thinning rates for the three values of $\alpha$ are similar. 


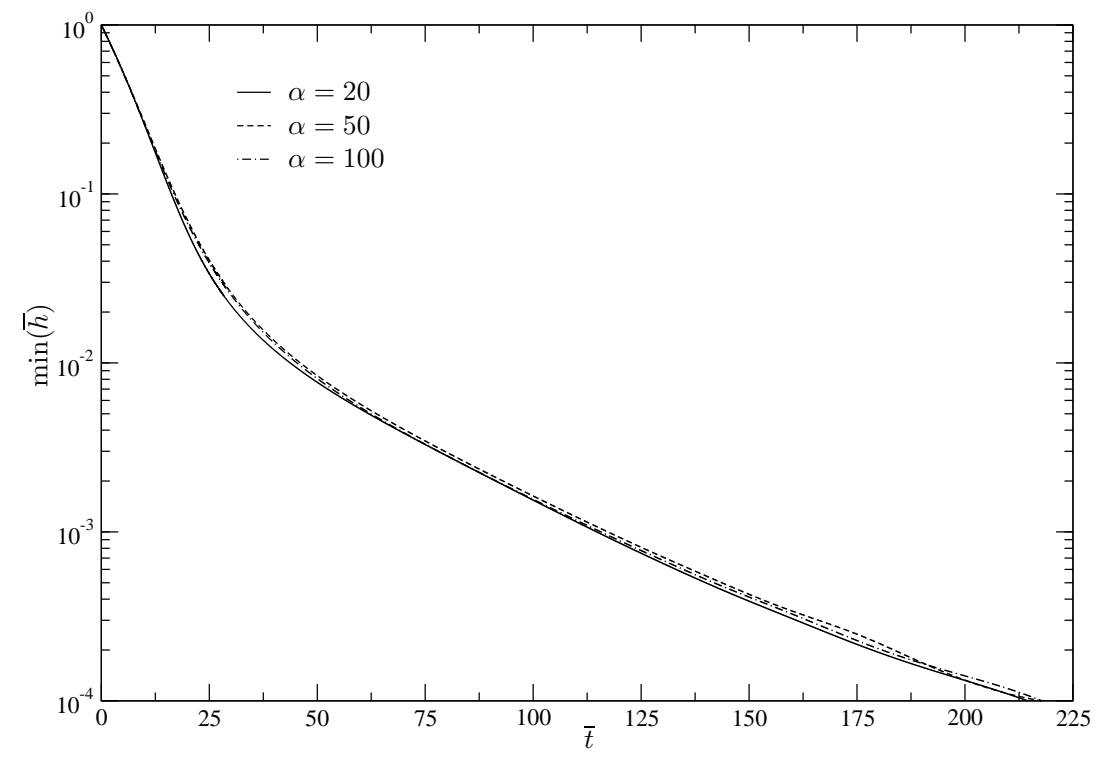

Figure 6: Minimum of $\bar{h}$ in the liquid film as a function of time for $\alpha=20,50$, and 100 .

In Figure 7, the film thickness is plotted versus $\bar{x}$ for the three values of $\alpha$ and four times. Close to the top, the profiles of $\bar{h}$ are similar whatever the value of $\alpha$. The main differences appear close to the bottom of the liquid film. The spread of the liquid film increases obviously with $\alpha$. Nevertheless, the difference between the results obtained with $\alpha=50$ and 100 are not very large for all times. Since except on top and bottom parts, the film thickness becomes small when $\bar{t}=40, \bar{h}$ has been rescaled for $\bar{x} \in[0.1 ; 0.6]$ and plotted in the insert of Figure 7-(d).

Figure 8 gives the velocity profile for the three values of $\alpha$ and the same times used in Figure 7. The main advantage of the boundary conditions (25) and (26) is that the velocity is not specified at the bottom but is a solution of the problem. Since the spread of the liquid film increases with $\alpha$, the velocity at the bottom is overestimated when $\alpha$ is small as a result of the mass conservation. The result is particularly true when $\alpha=20$ and $\bar{t}=20$. On the contrary, the velocity profiles are quasi-similar for $\alpha=50$ and 100. The velocity calculated at the bottom are very similar for these two values of $\alpha$. Nevertheless, when $\alpha=100$, a shoulder is observed for both times.

Finally, remark as it can be seen in Insert of Figure 8 when $\bar{t}=40$, the velocity is slightly negative close to the top of the liquid film as a consequence of the suction of the 

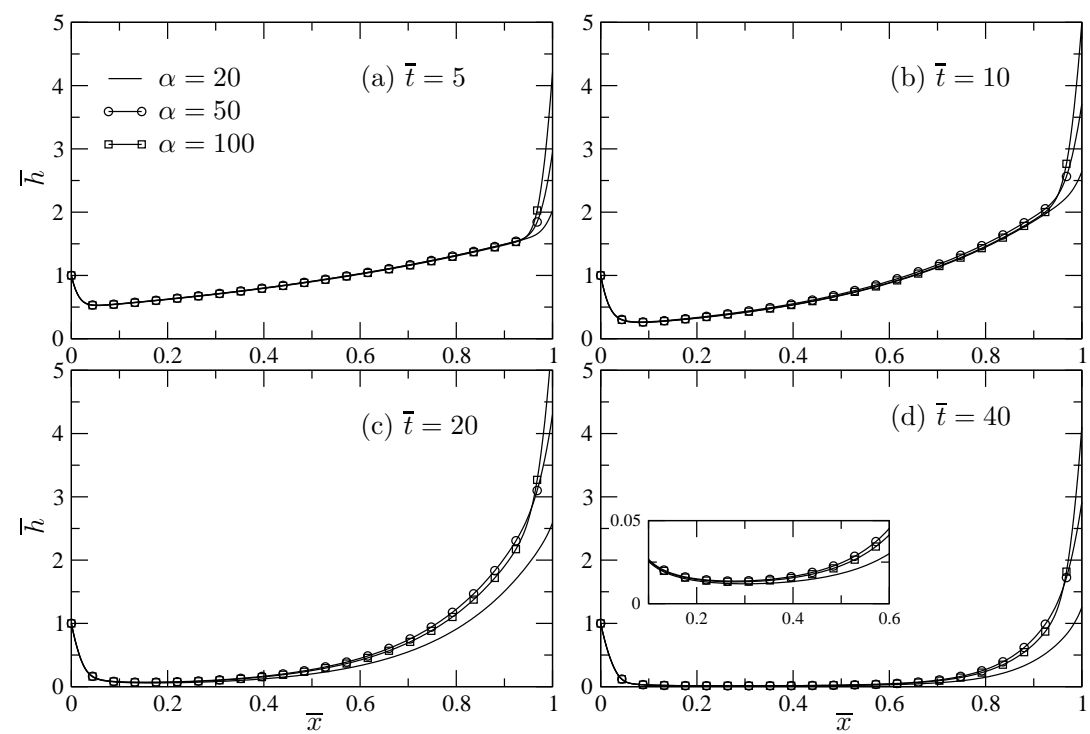

Figure 7: Film thickness, $\bar{h}$, as a function of $\bar{x}$ for $\alpha=20,50$, and 100 and for (a) $\bar{t}=5$, (b) 10, (c) 20 and (d) 40 .

boundary where the liquid film is thicker than the film thickness far away from the top boundary.

The results show that the boundary conditions given by Eqs. (25) and (26) are relevant to describe numerically the matching with the liquid pool and that drainage can be assumed independent on the boundary conditions parameter $\alpha$ once this parameter is larger than 50. In the following, numerical computations are done with $\alpha=100$.

\subsection{Effect of the surface tension gradient}

The surface tension and its gradient are determined for the same glass used in the previous subsection. The quantity $\delta \gamma$ given by (9) is equal to $4.2 \cdot 10^{-2} \mathrm{~N} / \mathrm{m}$ using the coefficient factors given by Rubenstein [25]. The conditions used in the numerical simulations are identical to these used in the previous subsection. The Marangoni number is equal to $2.02 \cdot 10^{-3}$.

First, the effect of $\bar{\delta}$ is addressed by plotting the minimum of $\bar{h}$ as a function of time. The numerical computations are operated until the minimum of $\bar{h}$ reaches the dimensionless value equal to $10^{-4}$ corresponding to a thickness around $100 \mathrm{~nm}$ for an initial thickness $H_{0}$ equal to $1 \mathrm{~mm}$. We assume that these dimensioned quantities are approx- 

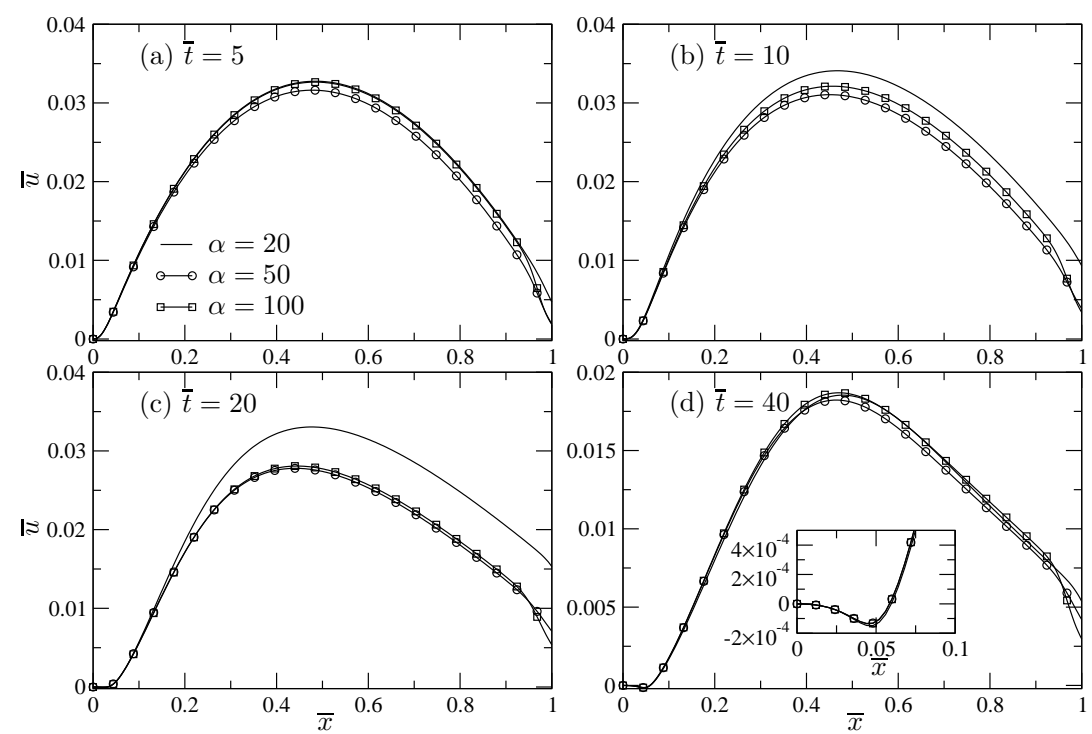

Figure 8: Film velocity, $\bar{u}$, as a function of $\bar{x}$ for $\alpha=20,50$, and 100 and for (a) $\bar{t}=5$, (b) 10 , (c) 20 and (d) 40.

imatively the maximum and minimum of thickness of the film during the experiment. Recall that the thickness of the frame is $1 \mathrm{~mm}$ and that film rupture for glass is around $100 \mathrm{~nm}$. Figure 9 shows the behavior of the minimum of the film thickness versus time for five values of $\bar{\delta}$. The case of $\bar{\delta}=0$ means that the surface tension gradient is equal to zero. When $\bar{\delta}=10^{-6}$, the surface tension gradient is too small to see an effect on the drainage for a typical thickness of $10^{-4}$. On the contrary, when $\bar{\delta}$ is larger than $10^{-6}$, the behavior of the film thickness changes strongly when $\bar{h}$ is sufficiently small. Indeed, a steady-state regime is observed after drainage. The asymptotic film thickness increases with $\bar{\delta}$ due to the surface tension gradient that acts sooner in time when $\bar{\delta}$ is larger.

It is noteworthy that, according to these numerical simulations, film thickness decreases by a factor $10^{4}$ over a dimensionless time approximatively equal to 220 . The experimental measurements for temperature lower than $1150^{\circ} \mathrm{C}$ (see Figure 2-a) give a lifetime around 500 in the same unit. Even if the disagreement between the experimental and the numerical results seems important, these first numerical analysis and experimental measurements are promising. Indeed, the experiences are difficult to control. We do not know accurately the pulling-out velocity and the initial thickness profile.

Film thickness profiles for $\bar{t}=200$ for the five values of $\bar{\delta}$ are plotted in Figure 10. The 


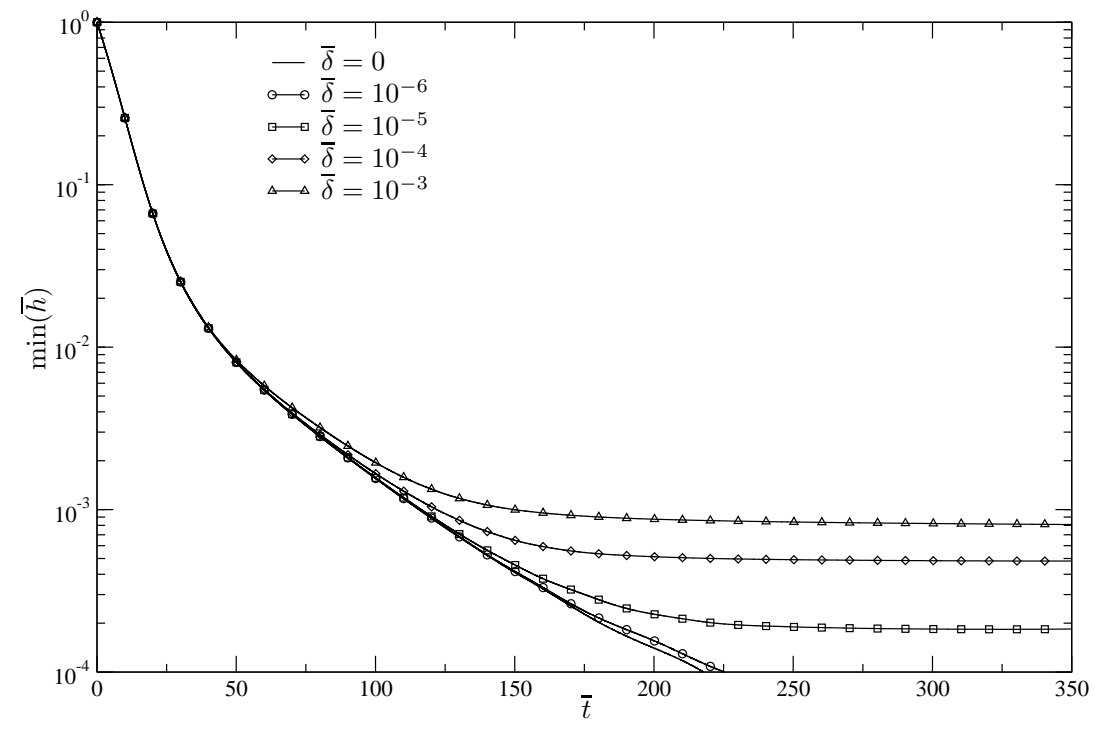

Figure 9: Minimum of $\bar{h}$ in the liquid film as a function of time for $\bar{\delta}=0,10^{-6}, 10^{-5}, 10^{-4}$ and $10^{-3}$.

film profile does not change for $\bar{\delta}$ equal to 0 and $10^{-6}$. For $\bar{\delta}=10^{-5}$, the film thickness is slightly thicker in the middle of the liquid film than for $\bar{\delta}<10^{-5}$. Close to the top and the bottom, the film thickness is very similar to the profiles obtained with $\bar{\delta}=0$ and $\bar{\delta}=10^{-6}$. For $\bar{\delta}>10^{-5}$, the shapes of the film profile are compared to the one computed for $\bar{\delta}=10^{-5}$, but with larger values.

The main differences are significant on the film velocity as it can be seen in Figure 11 where $\bar{u}$ is plotted versus $\bar{x}$ for the five values of $\bar{\delta}$. The typical velocity decreases by a factor 3 when $\bar{\delta}$ increases from 0 to $10^{-5}$. Remark, all profiles are close together near the bottom. The velocity profile observed for $\bar{\delta}=10^{-5}$ and $\bar{\delta}=10^{-4}$ does not change a lot apart from the top and the bottom. For the highest value of $\bar{\delta}\left(10^{-3}\right.$, the velocity decreases from the top to the bottom due to the largest heterogeneities in the film thickness observed in Figure 10, with a value less than the one obtained for $\bar{\delta}=10^{-4}$ close to the bottom.

With $\bar{\delta}=10^{-5}$, the film thickness reaches an asymptotic value equal to $1.8 \cdot 10^{-4}$. We note that this dimensionless depth and thickness correspond respectively to dimension values around $10^{-8} \mathrm{~m}$, which is close to the depth over which $\mathrm{Na}_{2} \mathrm{O}$ concentration varies according to SIMS analysis, and around $180 \mathrm{~nm}$ for asymptotic film thickness. Quanti- 


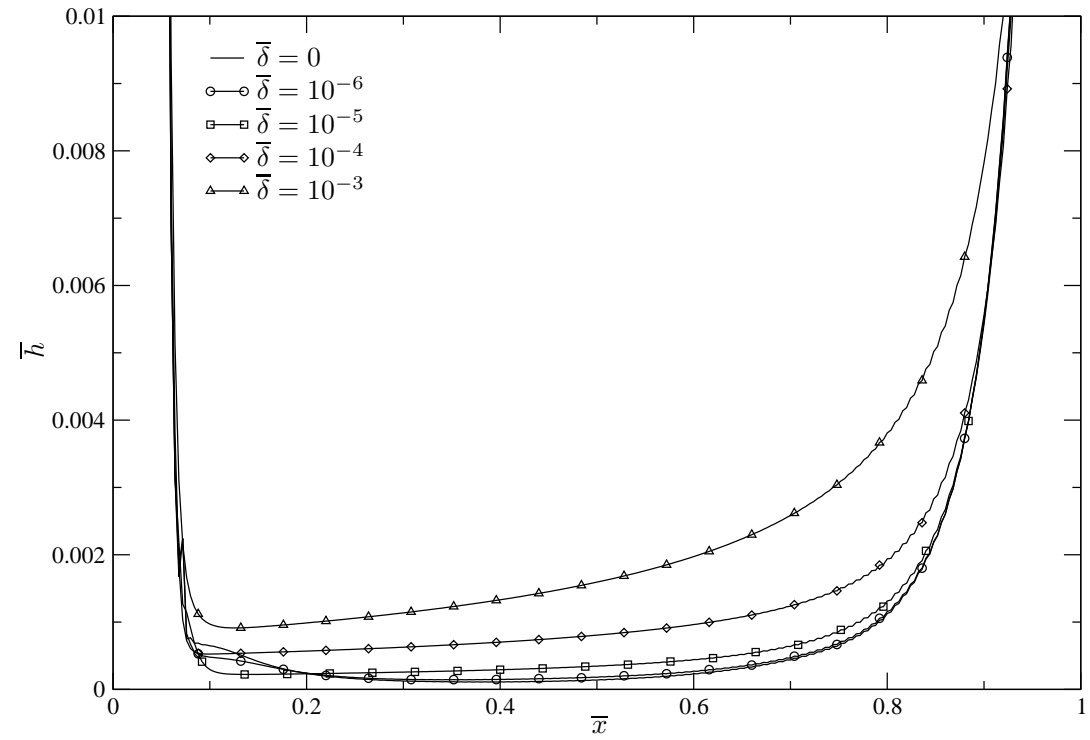

Figure 10: Film thickness, $\bar{h}$, as a function of $\bar{x}$ for $\bar{\delta}=0,10^{-6}, 10^{-5}, 10^{-4}$ and $10^{-3}$ when $\bar{t}=200$.

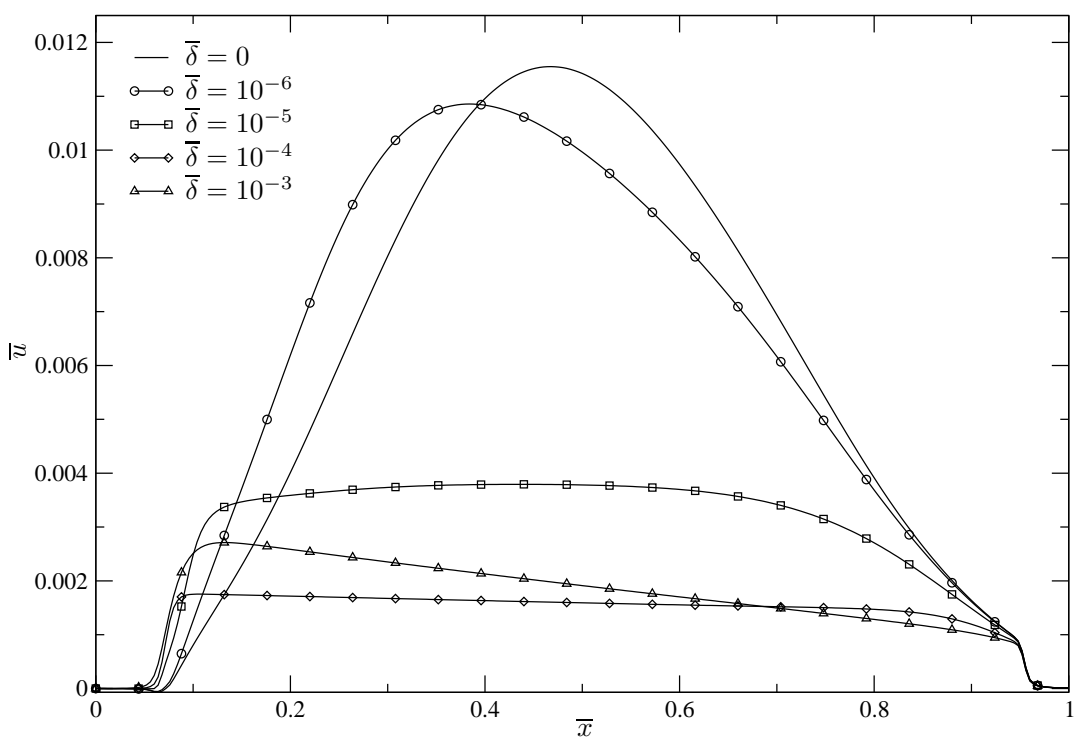

Figure 11: Film velocity, $\bar{u}$, as a function of $x$ for $\bar{\delta}=0,10^{-6}, 10^{-5}, 10^{-4}$ and $10^{-3}$ when $\bar{t}=200$. 
tatively as presented in section 2 this means that the surface tension varies in the range of $[1 ; 1.005]$. So, an increase of $0.5 \%$ is enough to stabilize the film thickness. Moreover, the equilibrium thickness found with this value are close to the experimental value given by Laïmbock [18] who found a value equal to $200 \mathrm{~nm}$. Kappel et al. [15] pointed out a value smaller $(100 \mathrm{~nm})$ but they did not measure the film thickness carefully. When $\bar{\delta}$ is larger than $10^{-5}$, the equilibrium thicknesses seem too large compared to the previous results given in $[18,15]$.

The experiments done in $[18,15]$ and the present one were achieved in laboratory furnaces where the thermal homogeneities must be controlled. Indeed, a thermal gradient can also changes the surface tension. Scholze [31] indicates a coefficient of surface tension thermal gradient equal around $4 \cdot 10^{-5} \mathrm{~N} /(\mathrm{m} \cdot \mathrm{K})$ meaning that to have an increase of 0.5 $\%$ of the surface tension, the difference of the temperature must be equal to $40 \mathrm{~K}$. This thermal difference must be appeared over the liquid length, typically few centimeters, which is too large with laboratory furnaces in which the thermal heterogeneities are usually less than $10 \mathrm{~K}$ in the area of working space. So, the stabilization of the liquid film must be mainly due to the chemical effect.

\section{Conclusion}

Drainage of vertical film of molten glass is investigated by reporting an experiment achieved at high temperature in a laboratory furnace. As expected, the observed lifetime decreases when temperature rises from 1100 to $1250^{\circ} \mathrm{C}$ because of a faster drainage due to decrease of bulk viscosity. However, we make evidence of an increase of lifetime for temperature larger than $1250^{\circ} \mathrm{C}$ that is correlated with the observation of patterns motion in the film. These motions are very similar to previously reported unstable motion generated by upward stresses that oppose regular gravitational drainage. We argue that these two phenomena are the consequence of the evaporation of surface active species like $\mathrm{Na}_{2} \mathrm{O}$ confirmed by a decrease of $\mathrm{Na}_{2} \mathrm{O}$ at proximity of the air/liquid interface measured by SIMS analysis. The evaporation has larger effect on surface tension in the area where the liquid film is thin than at the surface of the deep bath and thus generate upward Marangoni stresses. We quantitatively model the evolution of surface tension with film thickness by assuming that surface tension is the sum of the contribution of all chemical 
components present in volume and that mass loss per unit surface is function of film thickness.

A lubrication model is introduced to study the drainage of vertical liquid films. A surface tension gradient is introduced similarly to desorption/adsorption isotherm of thin film. The lubrication model coupled with surface tension variation is numerically solved with a finite difference method with an implicit time solver. The numerical procedure is applied to study the drainage of molten glass with a composition close to a window glass. We show that the chemical effect leading to the surface tension gradient can stabilize the liquid film at a thickness in agreement with observed results achieved by Laïmbock [18].

These results point out that even if a molten glass is usually considered as interface without "surfactant agents" (no amphiphilic molecules), the evaporation of oxides like $\mathrm{Na}_{2} \mathrm{O}$ from interface can lead to a stabilization of gravitational drainage of vertical film. This effect is very important for applications because it can explain why a significant foam layer appears in glass furnaces. Indeed, if the temperature for which the gas release in the bulk of molten glass is in the range where the evaporation of $\mathrm{Na}_{2} \mathrm{O}$ is significant to stabilize the liquid film, a foam layer can appear when the bubble flux coming from the glass bath is sufficiently important.

\section{References}

[1] R. G. C. Beerkens. Modeling the kinetics of volatilization from glass melts. J. Am. Ceram. Soc., 84:1952-1960, 2001.

[2] J. C. Berg, A. Acrivos, and M. Boudart. Evaporative convection. In Advances in Chemical Engineering, volume 6, pages 61-123. Academic Press Inc., New York, 1966.

[3] S. Berg, Z. A. Adelizzi, and S. M. Troian. Experimental study of entrainment and drainage flows in microscale soap films. Langmuir, 21:3867-3876, 2005.

[4] R. J. Braun, S. A. Snow, and S. Naire. Models for gravitationally-driven free film drainage. J. Eng. Math., 43:281-314, 2002.

[5] R. J. Braun, S. A. Snow, and U. C. Pernisz. Gravitational drainage of a tangentially immobile thick film. J. Colloid Interface Sci., 219:225-240, 1999.

[6] C. J. W. Breward. The mathematics of foam. PhD thesis, University of Oxford, 1999.

[7] I. Cantat, S. Cohen-Addad, F. Elias, F. Graner, R. Höhler, O. Pitois, F. Rouyer, and A. SaintJalmes. Les mousses. Structure et dynamique. Editions Belin, Paris, 2010.

[8] S. Cohen-Addad and J.-M. di Meglio. Stabilization of aqueous foam by hydrosoluble polymers. 2. Role of polymer/surfactant interactions. Langmuir, 10:773-778, 1994. 
[9] L. Collatz. The numerical treatment of differential equations. Springer-Verlag, Berlin, 1960.

[10] P.-G. de Gennes. "Young" soap films. Langmuir, 17:2416-2419, 2001.

[11] D. Exerowa and P. M. Kruglyakov. Foam and foam films. Theory, experiment, apllication. Elsevier, Amsterdam, 1998.

[12] M. Heller. Numerical study of free surfaces and particle sorting in microfluidic systems. PhD thesis, Technical University of Denmark, 2008.

[13] A. E. Hosoi and J. W. M. Bush. Evaporative instabilities in climbing films. J. Fluid Mech., 442:217-239, 2001.

[14] P. D. Howell. Models for thin viscous sheets. Eur. J. Appl. Math., 7:321-346, 1996.

[15] J. Kappel, R. Conradt, and H. Scholze. Foaming behaviour on glass melts. Glastech. Ber., 60:189$201,1987$.

[16] D.-S. Kim and P. Hrma. Foaming in glass melts produced by sodium sulfate decomposition under ramp heating conditions. J. Am. Ceram. Soc., 75:2959-2563, 1992.

[17] H. Kočárková. Stabilité des mousses de verre: Expériences à l'échelle d'une bulle ou d'un film vertical (in English). PhD thesis, Université Paris-Est, Marne la Vallée, 2011.

[18] P. Laimböck. Foaming of glass melts. PhD thesis, Technische Universiteit Eindhoven, 1998.

[19] S. Lionti-Addad and J.-M. di Meglio. Stabilization of aqueous foam by hydrosoluble polymers. 1. Sodium dodecyl sulfate-ply(ethylene oxide) system. Langmuir, 8:324-327, 1992.

[20] K. Mysels, K. Shinoda, and S. Frankel. Soap film. Studies of their thinning. Pergamon, New York, 1959.

[21] S. Naire, R. J. Braun, and S. A. Snow. An insoluble surfactant model for a vertical draining free film. J. Colloid Interface Sci., 230:91-106, 2000.

[22] A. Oron, S. H. Davis, and S. G. Bankoff. Long-scale evolution of thin liquid films. Rev. Mod. Phys., 69:931-980, 1997.

[23] L. Pilon. Foams in glass manufacture. In P. Stevenson, editor, Foam engineering: Fundamentals and Aplications.

[24] L. Pilon. Interfacial and transport phenomena in enclosed cell foam. PhD thesis, Purdue University, 2002.

[25] C. Rubenstein. Factors for the calculation of the surface tension of glasses at 1200 C. Glass Technol., 5:36-40, 1964.

[26] E. Ruckenstein and R. K. Jain. Spontaneous rupture of thin liquid films. J. Chem. Soc., Faraday Trans. 2, 70:132-147, 1974.

[27] K. J. Ruschak. Flow of a falling film into a pool. AIChE J., 24:705-709, 1978.

[28] D. M. Sanders and W. K. Haller. Effect of water vapor on sodium vaporization from two silica-based glasses. J. Am. Ceram. Soc., 60:138-141, 1977.

[29] L. Saulnier, F. Restagno, J. Delacotte, D. Langevin, and E. Rio. What is the mechanism of soap film entraintment? Langmuir, 27:13409-2011.

[30] B. Scheid, E. A. van Nierop, and H. A. Stone. Thermocapillary-assisted pulling of thin films: Application to molten metals. Appl. Phys. Lett., 97:171906-1-3, 2010. 
[31] H. Scholze. Glass. Nature, Structures and Properties. Springer-Verlag, Berlin, 1990.

[32] L. W. Schwartz and R. V. Roy. Modeling draining flow in mobile and immobile soap films. $J$. Colloid Interface Sci., 218:309-323, 1999.

[33] J. E. Shelby. Introduction to Glass Science and Technology. The Royal Society of Chemistry, Cambridge, 1997.

[34] F. T. Trouton. On the coefficient of viscous traction and its relation to that of viscosity. Proc. $R$. Soc. London, Ser. A, 77:426-440, 1906.

[35] J. van der Schaaf and R. G. C. Beerkens. A model for foam formation, stability, and breakdown in glass-melting furnaces. J. Colloid Interface Sci., 295:218-229, 2006.

[36] E. A. van Nierop, B. Scheid, and H. A. Stone. On the thickness of soap films: an alternative to Frankel's law. J. Fluid Mech., 602:119-127, 2008.

[37] E. A. van Nierop, B. Scheid, and H. A. Stone. On the thickness of soap films: an alternative to Frankel's law - CORRIGENDUM. J. Fluid Mech., 630:443, 2009.

[38] M. J. Varady and A. G. Fedorov. Combined radiation and conduction in glass foams. J. Heat Transfer, 124:1103-1109, 2002.

[39] A. Vrij. Possible mechanism for the spontaneous rupture of thin, free liquid films. Discuss. Faraday Soc., 42:23-33, 1966.

[40] R. G. Wilson, F. A. Stevie, and C. W. Magee. Secondary ion mass spectrometry: a practical handbook for depth profiling and bulk impurity analysis. John Wiley and Sons Inc, Hoboken (USA), 1989.

[41] S. D. R. Wilson and A. F. Jones. The entry of a falling film into a pool and the air-entrainment problem. J. Fluid Mech., 128:219-230, 1983. 